\title{
PREPARATION AND CHARACTERIZATION OF SODIUM CARBOXYMETHYL CELLULOSE FROM KAPOK (CEIBA PENTANDRA) ALPHA-CELLULOSE
}

\author{
PUTRI ZAHRA ARDIYANITA, SUTRIYO SUTRIYO, HERMAN SURYADI*
}

Faculty of Pharmacy, Universitas Indonesia, Depok 16424, Indonesia. Email: hsuryadi@farmasi.ui.ac.id

Received: 02 October 2009, Revised and Accepted: 24 December 2019

\section{ABSTRACT}

Objective: This study aimed to obtain sodium carboxymethyl cellulose (NaCMC) from $\alpha$-cellulose of the hulls of kapok (Ceiba pentandra) and determining its identity and characteristics base on compendial requirements and compared to the reference (standard).

Methods: $\alpha$-Cellulose was isolated from kapok hulls and used to generate NaCMC powder through alkalization and carboxymethylation. Alkalization was performed using $25 \% \mathrm{NaOH}$ (containing sodium tetraborate), whereas carboxymethylation was using sodium monochloroacetate. Identification and characterization were performed through infrared spectrum analysis using Fourier transform infrared, qualitative analysis, organoleptic examination, morphologic examination, and topographical analysis using scanning electron microscopy (SEM), and X-ray diffraction. Tests conducted were $\mathrm{pH}$ determination, sulfated ash content, moisture content, loss on drying, particle density, and viscosity.

Results: The obtained NaCMC powder was yellowish-white with a similar infrared spectrum as the NaCMC standard. The powder had a degree of substitution of 0.57 and a pH of 8.5. According to SEM, the obtained powder had a similar morphology as the NaCMC standard, although the synthesized NaCMC had a rougher surface. The obtained NaCMC also had a similar diffractogram as the NaCMC standard, which was characterized by the presence of crystalline and amorphous structures. Besides, the NaCMC powder had a similar moisture content (8.50\%), sulfated ash content (36.43\%), and loss on drying (9.87\%) as the standard, whereas its $1 \%$ viscosity value $(20.6 \mathrm{cP})$ was substantially different.

Conclusion: NaCMC generated from $\alpha$-cellulose of kapok hulls fulfills compendial requirements and has similar characteristics to reference.

Keywords: Kapok, Sodium carboxymethyl cellulose, Alkalization, Carboxymethylation, Characterization.

(C) 2020 The Authors. Published by Innovare Academic Sciences Pvt Ltd. This is an open access article under the CC BY license (http://creativecommons. org/licenses/by/4. 0/) DOI: http://dx.doi.org/10.22159/ijap.2020.v12s1.25840

\section{INTRODUCTION}

Cellulose is an important commodity for various industries, such as the pharmaceutical industry. A commonly used cellulose derivative in the pharmaceutical industry is sodium carboxymethyl cellulose (NaCMC), which used in pharmaceutical preparations, including oral and topical preparations. NaCMC is used to increase viscosity and stabilize emulsions. Besides, NaCMC also functions as a binder and disintegrant in tablet preparations [1].

Initially, NaCMC was produced from wood because it contains high cellulose levels (42-47\%) [2]. However, the current trend is the production of NaCMC from non-wood lignocellulosic materials due to the limited availability of wood and increasing prices. One of them is kapok (Ceiba pentandra), which is abundantly available in Indonesia.

Kapok has the potential for use as a raw material for producing NaCMC because it contains $\alpha$-cellulose with a purity level of $94.05 \%$ [3]. Cellulose isolated from kapok hulls can be synthesized into NaCMC through alkalization using $\mathrm{NaOH}$ and carboxymethylation using sodium monochloroacetate (NaMCA).

This study aimed to identify the optimal reaction conditions for synthesizing NaCMC from kapok $\alpha$-cellulose to fulfill compendial testing requirements.

\section{MATERIALS AND METHODS}

\section{Raw material}

The raw material used in this study was kapok hulls powder obtained from Balitro, Bogor, West Java Province, Indonesia.
Chemical material

The chemicals used were $96 \%$ ethanol, nitric acid, sodium hydroxide, sodium sulfite, sodium hypochlorite, NaMCA, sodium tetraborate, isopropyl alcohol, $\mathrm{KBr}$ powder, glacial acetic acid, methanol, sulfuric acid, orange methyl P, phenolphthalein, $\alpha$-naphthol, anhydrous sodium carbonate, potassium bisulfate, and standard NaCMC powder as a comparator which were from Merck (Germany). Besides, distilled water was obtained from Brataco (Indonesia).

\section{Instruments}

The instruments used in this study included an infrared spectrophotometer (FTIR-8400S Shimadzu, Japan), analytical balance (Sartorius, Germany), a bulk density tester (BDT M4-005/04, Indonesia), a furnace (Cole-Parmer, USA), a hot plate and stirrer (IKA Type Hs-7, Germany), a scanning electron microscope (SEM) (QUANTA 650, USA), and X-ray diffraction (XRD) system (Panalytical X'Pert Pro MPDb, Europe), a moisture analyzer (ADAM AMB50, USA), a viscometer (Cole-Parmer), a sintered funnel (Pyrex, Germany), filter paper (Whatman, Germany), aluminum foil (Total Wrap, Indonesia), a crucible (PRC, China), an oven (Heraeus, Germany), a desiccator (Duran, Germany), and a burette (Pyrex) and other glassware commonly used in laboratories.

\section{Isolation of $\alpha$-cellulose from kapok hulls}

In total, $200 \mathrm{~g}$ of kapok shell powder were mixed with $2.67 \mathrm{~L}$ of $3.5 \%$ nitric acid (containing $26.7 \mathrm{mg}$ of sodium nitrite) at $90^{\circ} \mathrm{C}$ for $2 \mathrm{~h}$. Then, the residue was immersed in $2 \mathrm{~L}$ of a solution containing sodium hydroxide and sodium sulfite at a concentration of $2 \% \mathrm{~b} / \mathrm{v}$ at $50^{\circ} \mathrm{C}$ for $1 \mathrm{~h}$ and bleached through boiling in a $1.3 \mathrm{~L}$ of a $1: 1$ mixture of water and $3.5 \%$ sodium hypochlorite. The obtained residue was heated in $1.3 \mathrm{~L}$ 
of sodium hydroxide $(17.5 \% \mathrm{~b} / \mathrm{v})$ at $80^{\circ} \mathrm{C}$ for $30 \mathrm{~min}$. The residue was then dried at $60^{\circ} \mathrm{C}$ and crushed to obtain $\alpha$-cellulose powder [4].

\section{Preparation of NaCMC from kapok $\alpha$-cellulose}

First, $3 \mathrm{~g}$ of $\alpha$-cellulose were weighed and placed in a glass beaker containing $60 \mathrm{~mL}$ of isopropyl alcohol. Then, $25 \% \mathrm{NaOH}$ (containing 0.17 g sodium tetraborate) was added to a volume of $10 \mathrm{~mL}$, and the mixture was stirred for $1 \mathrm{~h}$ at $25^{\circ} \mathrm{C}$. Furthermore, the carboxymethylation process was optimized by varying the amount of NaMCA (3.75, 3.90, and $4.05 \mathrm{~g}$ ) with constant stirring at $55^{\circ} \mathrm{C}$. The reaction time was $3.5 \mathrm{or}$ $4 \mathrm{~h}$ for $3.75 \mathrm{~g}$ of NaMCA, 2.5 or $3 \mathrm{~h}$ for $3.90 \mathrm{~g}$ of NaMCA, and 1.5 or $2 \mathrm{~h}$ for $4.05 \mathrm{~g}$ of NaMCA. The obtained product was filtered and suspended in $60 \mathrm{~mL}$ of methanol. The slurry was neutralized with glacial acetic acid. The final product was washed with $80 \%$ ethanol and methanol, followed by filtration and drying in an oven at $60^{\circ} \mathrm{C}$ to obtain NaCMC powder, which was stored in a desiccator [4].

\section{Organoleptic examination}

The product examinations were shape, color, taste, and odor in comparison with the NaCMC standard commonly used as a pharmaceutical excipient.

\section{Identification using Fourier transform infrared (FTIR)}

After mixing $99 \mathrm{mg}$ of $\mathrm{KBr}$ with $1 \mathrm{mg}$ of each sample, scanning was over the wavelength range of $4000-400 \mathrm{~cm}^{-1}$. The IR spectrum of each sample was compared with that of the standard.

\section{Qualitative analysis}

One gram of sample was added to $50 \mathrm{~mL}$ of water. A sample solution of $1 \mathrm{~mL}$ was mixed with $1 \mathrm{~mL}$ of distilled water, and five drops of $\alpha$-naphthol. Then, $2 \mathrm{~mL}$ of concentrated sulfuric acid was added to the solution, which turned purple. The results were compared to the NaCMC standard following the same procedure [5]

\section{Degree of substitution (DS)}

One gram of $\mathrm{NaCMC}$ was put into $20 \mathrm{~mL}$ of $95 \%$ ethanol and stirred for $5 \mathrm{~min}$. Then, $5 \mathrm{~mL}$ of $2 \mathrm{M}$ nitric acid was added, and the mixture was brought to a boil followed by continuous stirring at $80^{\circ} \mathrm{C}$ for $10 \mathrm{~min}$. The liquid phase that formed was removed, and the solid phase was washed 5 times, with $10 \mathrm{~mL}$ of $80 \%$ ethanol at $60^{\circ} \mathrm{C}$. The precipitate was washed with $10 \mathrm{~mL}$ of methanol. Finally, the precipitate was dried at $100^{\circ} \mathrm{C}$ for $3 \mathrm{~h}$ and refrigerated in a desiccator for $30 \mathrm{~min}$. Then, $0.5 \mathrm{~g}$ of dried NaCMC was weighed, and $100 \mathrm{~mL}$ of distilled water was added. Then, $25 \mathrm{~mL}$ of $0.3 \mathrm{M} \mathrm{NaOH}$ was added, and the mixture was heated to a boil for $15 \mathrm{~min}$. After the sample dissolved, two drops of a phenolphthalein indicator were added, causing the solution to turn pink, and the solution was hydrated with $0.3 \mathrm{M} \mathrm{HCl}$ until the pink color disappeared [6]. The DS of NaCMC was calculated as follows:

$$
\mathrm{DS}=\frac{162 \times \% \mathrm{CM}}{5900-(58 \times \% \mathrm{CM})}
$$

$$
\% \mathrm{CM}=\frac{(\text { Blank volume }-\mathrm{HCl} \text { volume }) \times \mathrm{HClmolarity} \times 0.059 \times 100}{\text { Samplemass }(\mathrm{g})}
$$

\section{pH test}

One gram of $\mathrm{NaCMC}$ was dispersed into $100 \mathrm{~mL}$ of distilled water, and the $\mathrm{pH}$ was measured using a $\mathrm{pH}$ meter.

\section{SEM}

SEM was performed to assess the surface morphology of each sample. Imaging was performed after selecting a certain part of the object (sample) and the desired magnification $(\times 150$ and $\times 600)$ to ensure that a clear photo was obtained. This analysis was conducted for both synthesized samples and the NaCMC standard.

\section{XRD analysis}

XRD analysis was performed to assess the crystalline and amorphous forms of NaCMC. First, $2 \mathrm{~g}$ of each sample were smoothed and placed on the glass with the help of an adhesive, followed by characterization.

\section{Moisture content}

Water content can be measured using the moisture content (Adam) at $105^{\circ} \mathrm{C}$. First, $1 \mathrm{~g}$ of each sample was weighed on top of an aluminum plate that was previously anchored. The tool then measured the sample water content.

\section{Sulfated ash content}

Ash content was measured using a furnace. A crucible was heated in a furnace at $600 \pm 50^{\circ} \mathrm{C}$ for $30 \mathrm{~min}$, cooled in a desiccator, and weighed. As much as, $1 \mathrm{~g}$ of each sample was weighted in the crucible. The sample was then wetted using sulfuric acid $(1 \mathrm{~mL})$ and heated until it was charred. After cooling, the residue was wetted with a small amount of sulfuric acid and heated it until the white smoke disappeared. Then, the crucible was heated at $600 \pm 50^{\circ} \mathrm{C}$ until the residue burned completely. The crucible was placed in a desiccator until it was cold and weighed, and then the percentage of ash was calculated [7].

\section{Loss on drying}

Samples of NaCMC ( $1 \mathrm{~g})$ were weighed in a crucible and then dried in an oven at $105^{\circ} \mathrm{C}$ until they reach a constant weight.

\section{Density test}

Samples of NaCMC (15 g) were weighed and placed in a $50-\mathrm{mL}$ measuring cup with a polygonal bottom. The volume was recorded as the bulk volume. Next, the measuring cup was placed on the tool, which was activated. When the appliance stopped, the final volume was recorded as the tapped volume.

\section{Viscosity test (1\%)}

As much as, $1 \mathrm{~g}$ of NaCMC was weighed, dissolved in $100 \mathrm{~mL}$ of distilled water, and stirred until homogeneous, followed by testing for viscosity using a viscometer.

\section{RESULTS AND DISCUSSION}

\section{Preparation of $\alpha$-cellulose from kapok hulls}

The isolation of $\alpha$-cellulose from kapok hulls begins with delignification using 3.5\% nitric acid containing sodium nitrite. In this process, nitric acid will degrade the lignin bond structure, permitting lignin to separate from cellulose [8]. Sodium nitrite is added to accelerate the degradation process. Nitric acid cannot eliminate lignin, and thus, the second round of delignification was performed using a mixture of $2 \%$ sodium sulfite $/ 2 \%$ sodium hydroxide followed by bleaching using a mixture of 3.5\% sodium hypochlorite and water. Sodium hypochlorite can remove lignin residue in the pulp. Furthermore, $\alpha$-cellulose, $\beta$-cellulose, and $\gamma$-cellulose were separated using $17.5 \%$ sodium hydroxide [9]. Cellulose was heated at $100^{\circ} \mathrm{C}$ to obtain $\alpha$-cellulose from kapok fibers (Fig. 1).

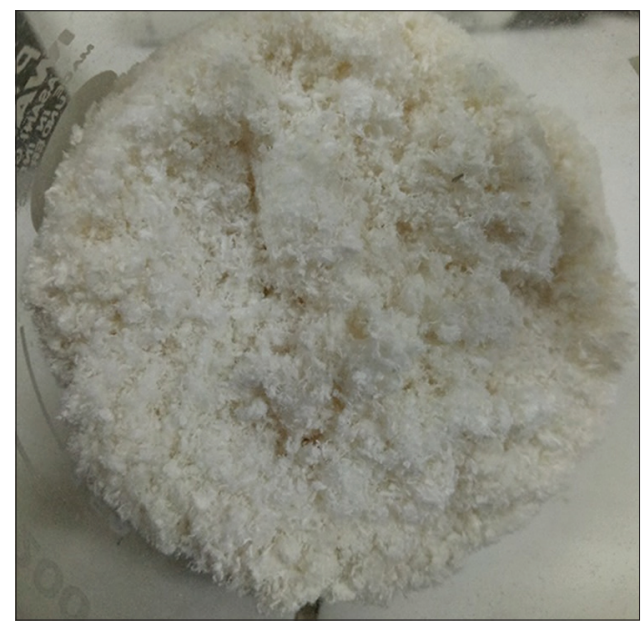

Fig. 1: $\alpha$-Cellulose isolated from kapok hulls 
Optimization and preparation of NaCMC from $\alpha$-cellulose

NaCMC is synthesized in two stages, namely, alkalization and carboxymethylation. Alkalization was performed by stirring $\alpha$-cellulose in isopropyl alcohol and then adding $25 \% \mathrm{NaOH}$ containing sodium tetraborate. Isopropyl alcohol functions as a reaction medium that affects the quality of NaCMC. A smaller polarity of the reaction medium can increase the reaction rate of NaCMC formation [2]. The use of isopropyl alcohol as a reaction medium also results in relatively fewer byproducts (sodium glycolate) [6]. $\mathrm{NaOH}$ converts cellulose into alkali cellulose. Sodium tetraborate can improve the quality of NaCMC by indirectly increasing the DS of the synthesized products [10].

The product synthesized through alkalization was alkali cellulose, which was reacted with NaMCA to form NaCMC through carboxymethylation. NaMCA functions as an etherification reagent that induces the substitution of sodium carboxymethyl groups at C2, C3, and C6 [11]. The carboxymethylation stage was optimized by varying the amount of NaMCA and the duration of the reaction, in line with prior research illustrating that varying the conditions of carboxymethylation altered the DS results [4].

After completing both stages, the formed product was separated into its liquid and solid phases. The solid phase was immersed in absolute methanol and neutralized with glacial acetic acid. The mixture was filtered, and then the residue was washed 3 times, with $80 \%$ to remove the remnants of the byproducts formed. Finally, the residue was again washed with absolute methanol, filtered, and dried. The DS of the synthesized NaCMC was examined as a quality parameter.

Based on the experiments conducted, the largest DS value of 0.59 was obtained using $3.75 \mathrm{~g}$ of NaMCA and a reaction time of $3.5 \mathrm{~h}$. A small DS value was obtained because the carboxymethyl group was not substituted well on $\alpha$-cellulose from kapok. Therefore, it was necessary to optimize other parameters (e.g., temperature, reaction medium, and $\mathrm{NaOH}$ levels) to optimize NaCMC synthesis. Although the DS value did not meet the requirements, the optimal conditions regarding NaMCA treatment ( $3.5 \mathrm{~g}$ of NaMCA, a reaction time of $3.5 \mathrm{~h}$ ) were selected to synthesize NaCMC from $\alpha$-cellulose. Furthermore, identification and characterization of NaCMC from kapok cellulose were performed in comparison to the NaCMC standard.

\section{Organoleptic examination}

According to the organoleptic examination, the NaCMC standard and NaCMC from kapok $\alpha$-cellulose have no smell and taste. However, there was a slight difference in color between the two moieties. The NaCMC standard had a white color, whereas NaCMC synthesized from kapok $\alpha$-cellulose had a yellowish-white color. A difference in color occurred because of the presence of residual lignin that was not completely dissolved in the bleaching process. Besides, the two powders exhibited slight differences in texture. NaCMC synthesized from $\alpha$-kapok cellulose had a finer powder texture than the NaCMC standard, which had a texture similar to that of cotton fibers.

\section{Identification using FTIR}

Infrared spectrometry was performed to determine the suitability of $\alpha$-cellulose and NaCMC functional groups. The spectrum of kapok $\alpha$-cellulose was compared with Avicel PH-101 (Fig. 2), whereas NaCMC synthesized from $\alpha$-cellulose was compared with the NaCMC standard commonly used in pharmaceutical preparations (Fig. 3).

The functional groups in the structure of $\alpha$-cellulose include $\mathrm{OH}$ groups at 3650-3200 $\mathrm{cm}^{-1}$, stretched CH groups at $3000-2850 \mathrm{~cm}^{-1}$, and COC bonds at $1200-980 \mathrm{~cm}^{-1}[11,12]$. The spectra of Avicel PH-101 and $\alpha$-cellulose from kapok were similar, and thus, it can be stated that the compound produced in the isolation process was $\alpha$-cellulose and that it could be used for the next stage, namely, NaCMC synthesis [12].

Based on its structure, NaCMC has similar functional groups as $\alpha$-cellulose. However, NaCMC possessed a carbonyl group $(-\mathrm{C}=0)$ at 1800-1670 $\mathrm{cm}^{-1}$, which indicated the presence of a carboxymethyl substitution. A peak indicated the presence of $\mathrm{CH} 2$ at 1425$1421 \mathrm{~cm}^{-1}[11,12]$. Based on these data, the NaCMC standard and NaCMC synthesized from kapok $\alpha$-cellulose have similarities.

\section{Qualitative analysis}

Qualitative analysis was performed to determine the presence of glucose in NaCMC. The NaCMC standard was used as a positive control, and samples containing no NaCMC were used as negative controls.

The negative control did not have a purple color, unlike the NaCMC standard, and NaCMC synthesized from kapok hulls. This difference in color can be attributed to the addition of $\alpha$-naphthol and sulfuric acid [5]. NaCMC is dehydrated when reacted with sulfuric acid, thus forming a furfural structure that will then condense with $\alpha$-naphthol to produce a purple compound (Fig. 4) [13].

\section{DS}

The NaCMC standard had a DS value of 0.77 , which met the requirements (0.7-1.2). Conversely, the synthesized NaCMC had a DS value of 0.57 . This rather low value of NaCMC from kapok $\alpha$-cellulose was unique and can be caused by different raw material from NaCMC standard.

\section{pH test}

The $\mathrm{pH}$ of the NaCMC standard was 6.98, versus 8.50 for the synthesized $\mathrm{NaCMC}$, both of which fell into the desired range (6.5-8.5). Although the requirements were met, some results failed to meet the standard. This negative result, possibly due to some NaCMC samples, contained high levels of $\mathrm{NaOH}$ because of a lack of neutralization process.

\section{SEM}

SEM analysis revealed similarities between the synthesized NaCMC and the NaCMC standard. Morphologically, the NaCMC standard had a stemlike structure arranged separately with a smooth surface. Meanwhile, NaCMC synthesized from kapok $\alpha$-cellulose was in the form of rods that formed clot-like masses and had a slightly rough surface (Fig. 5). The morphological differences between these two types of NaCMC can be attributed to the different sources of raw materials ( $\alpha$-cellulose) used.

\section{XRD analysis}

The NaCMC standard (Fig. 6) had a typical diffractogram pattern featuring a sharp peak at a $2 \theta$ of 20.2825 , which denoted the nature of the crystal. Besides, the diffractogram also exhibited a wide peak at $2 \theta$ of 38.0465, which denoted its amorphous properties. For the synthesized NaCMC (Fig. 7), a similar diffractogram pattern with a sharp peak at a $2 \theta$ of 20.4161 was recorded, illustrating the crystalline structure. The diffractogram additionally displayed a wide peak, although it was not clear, at a $2 \theta$ of 39.2665 , which reflected its amorphous properties. Thus, crystalline and amorphous forms were identified for both the NaCMC standard and NaCMC produced from kapok $\alpha$-cellulose.

\section{Moisture content}

The NaCMC standard had a water content of $5.75 \%$, compared with $8.50 \%$ for the synthesized NaCMC. Both values met the moisture content requirement of $<10 \%$.

The sulfated ash content of the NaCMC standard was $23.87 \%$, versus $36.43 \%$ for the synthesized NaCMC. The latter figure did not meet the sulfated ash content requirement (20-33.3\%). The high sulfated ash content of the synthesized NaCMC could be attributable to a large number of metals, such as sodium, that are not eliminated during the combustion process [14].

\section{Loss on drying}

The results illustrated that the NaCMC lost $8.69 \%$ of its weight on drying, compared with $9.87 \%$ for the synthesized NaCMC. These results indicate that both forms of NaCMC met the requirement for loss on drying $(<10 \%)$.

\section{Density test}

According to the test results, the NaCMC standard had a bulk density of $0.37 \mathrm{~g} / \mathrm{cm}^{3}$ and a tapped density of $0.56 \mathrm{~g} / \mathrm{cm}^{3}$, whereas $\mathrm{NaCMC}$ 


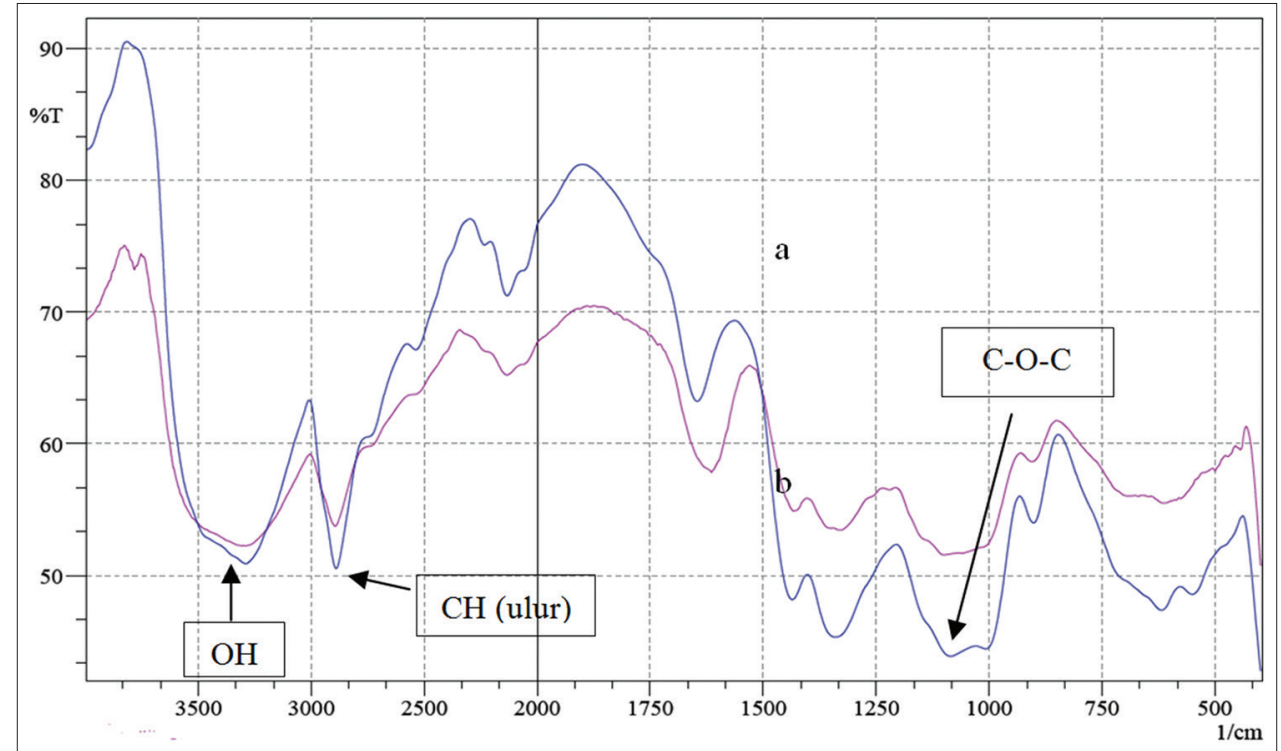

Fig. 2: Fourier transform infrared spectra of Avicel PH-101 (blue) and (b) $\alpha$-cellulose isolated from kapok hulls (pink)

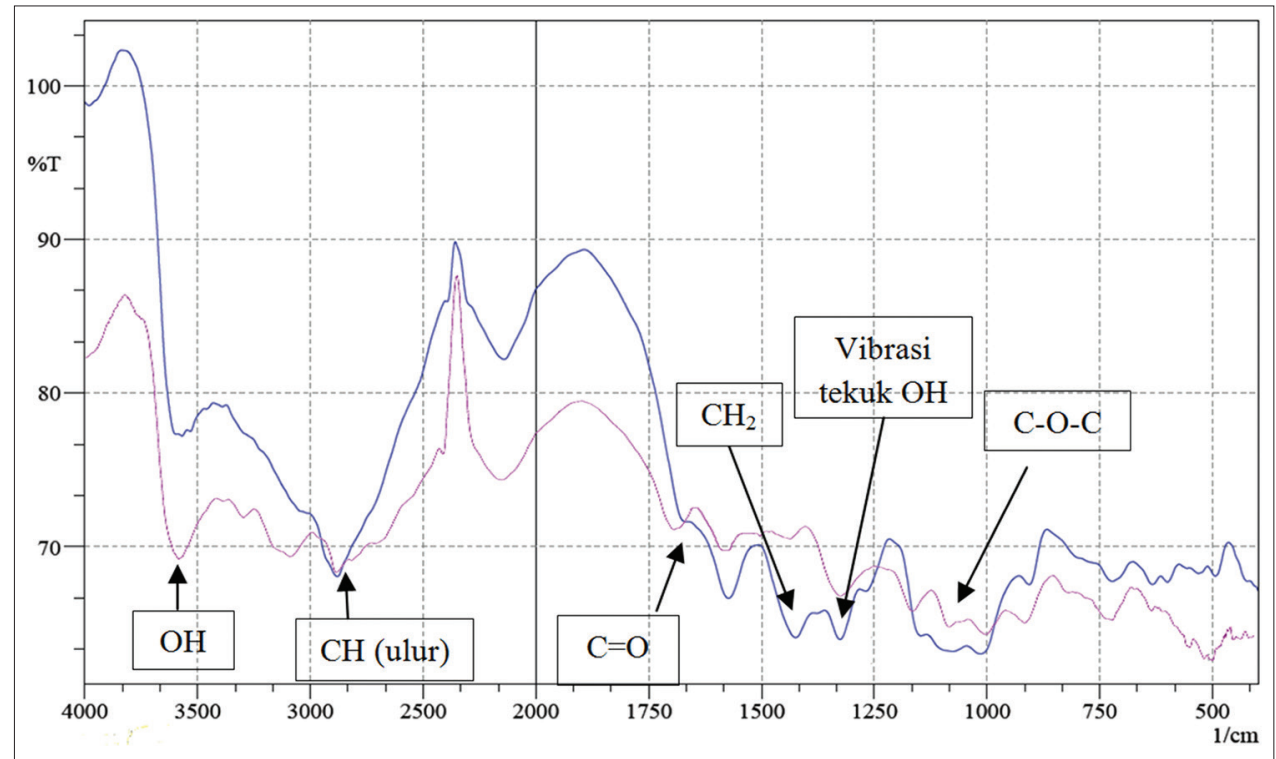

Fig. 3: Fourier transform infrared spectra of sodium carboxymethyl cellulose (NaCMC) standard (blue) and NaCMC synthesized from kapok $\alpha$-cellulose (pink)

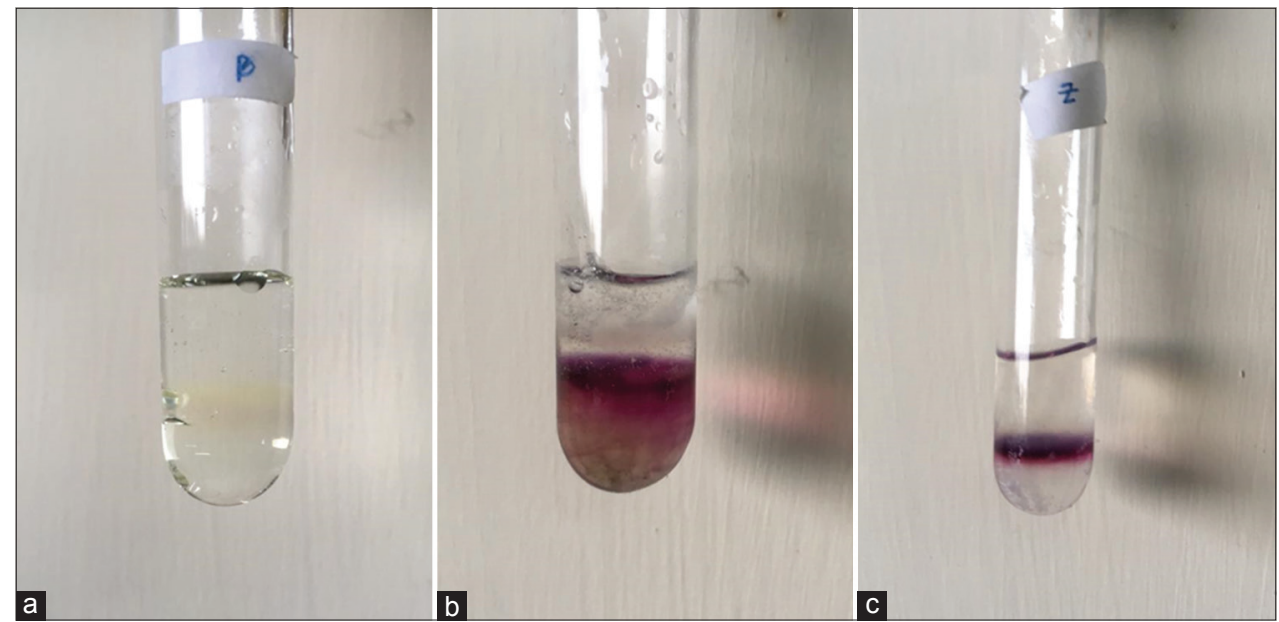

Fig. 4: (a) Negative control, (b) positive control, and (c) sample 

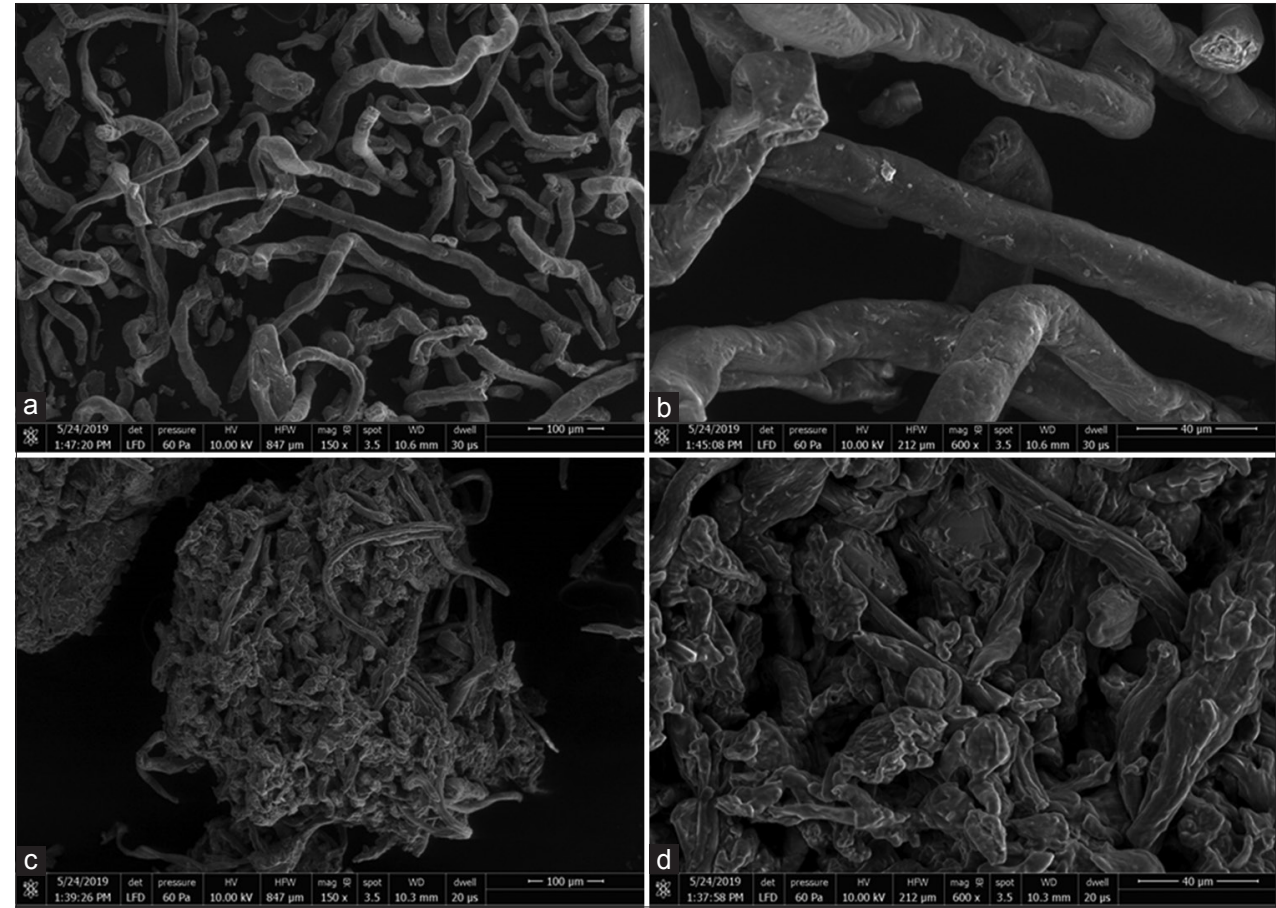

Fig. 5: (a) Sodium carboxymethyl cellulose (NaCMC) standard, $\times 150$, (b) NaCMC standard, $\times 600$, (c) NaCMC synthesized from kapok $\alpha$-cellulose, $\times 150$, (d) NaCMC synthesized from kapok $\alpha$-cellulose, $\times 600$

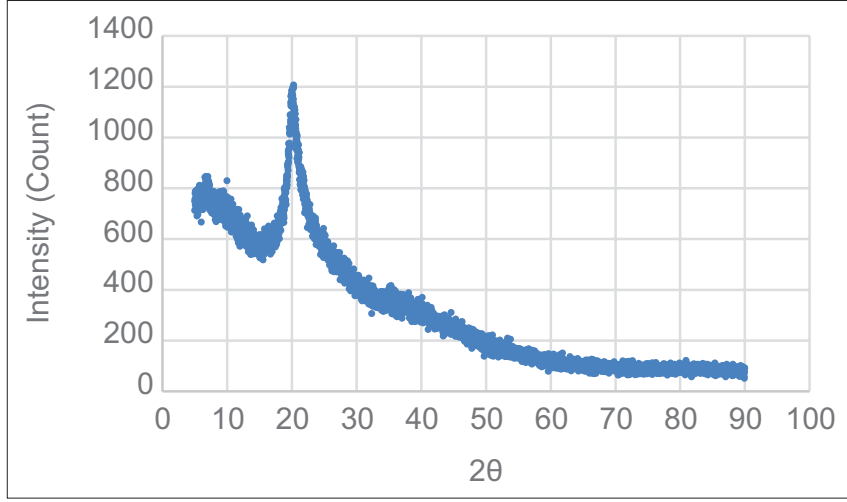

Fig. 6: Diffractogram of the sodium carboxymethyl cellulose standard

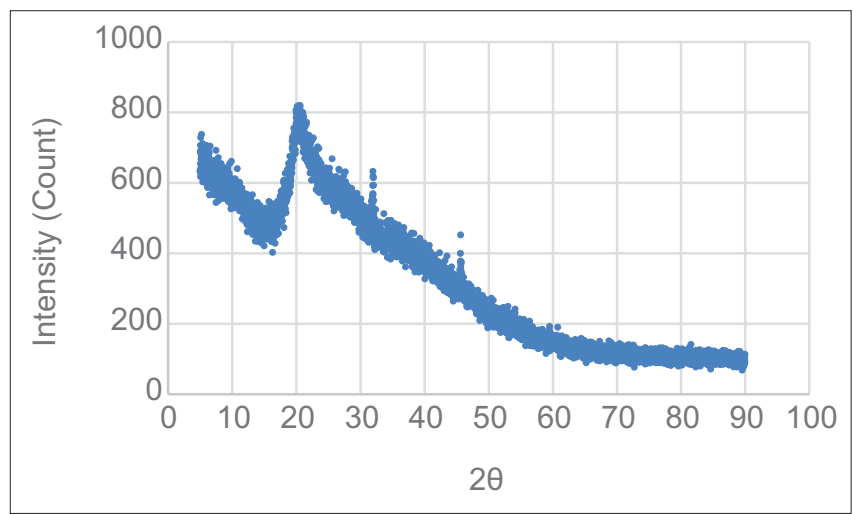

Fig. 7: Diffractogram of sodium carboxymethyl cellulose synthesized from kapok $\alpha$-cellulose

synthesized from kapok $\alpha$-cellulose had a bulk density $0.47 \mathrm{~g} / \mathrm{cm}^{3}$ and a tapped density $0.55 \mathrm{~g} / \mathrm{cm}^{3}$. These results indicate that neither the standard nor the product met the requirements for bulk or tapped density.

The smaller density of the NaCMC standard can be attributed to its lighter mass, giving it a relatively larger volume but smaller density than the synthesized NaCMC. Furthermore, the shape of synthesized $\mathrm{NaCMC}$ particles was more rounded than that of the NaCMC standard, which decreased the space between particles and the resulting volume, leading to greater density [15].

\section{Viscosity test (1\%)}

The viscosity of the NaCMC standard was $3528.5 \mathrm{cP}$, versus $20.6 \mathrm{cP}$ for the synthesized NaCMC. Although both values met the stated viscosity requirement, they were substantially different. This difference can be explained by the different sources used to generate the materials.

\section{CONCLUSION}

As the conclusion, based on the characteristics data obtained, the synthesized NaCMC had a similar morphology to the standard and also showed identity and characteristics similar to the reference. The substantial difference is only its viscosity that possibly due to the different raw material used.

\section{ACKNOWLEDGMENT}

We thank the Directorate of Research and Community Engagement of Universitas Indonesia for financial support (Hibah QQ no. NKB-0198/ UN2.R3.1/HKP.05.00/2019) to our study.

\section{CONFLICTS OF INTEREST}

None.

\section{REFERENCES}

1. Rowe RC, Sheskey PJ, Quinn ME. Handbook of Pharmaceutical Excipients. Vol. 40. 2015. p. 9823. Available from: https://www. mendeley.com/research/hhzcivah-d-evgbvxzjixva-8zbhign-1.

2. Pitaloka AB, Hidayah NA, Saputra AH, Nasikin M. Pembuatan CMC dari selulosa eceng gondok dengan media reaksi campuran larutan 
isopropanol-isobutanol untuk mendapatkan viskositas dan kemurnian tinggi. J Integr Proses 2015;5:108-14

3. Astika JM, Chandrawati C, Hendrajaya L, Yogi PS. The exploration of alpha cellulose in kapok fruit as raw material for rocket propellant production. Agric Res Technol 2017;12:1-8.

4. Alizadeh AS, Mousavi M, Labbafi M. Synthesis and characterization of carboxymethyl cellulose from sugarcane bagasse. J Food Process Technol 2017;8:687.

5. The United States Pharmacopeial Convention. Carboxymethylcellulose Sodium. $30^{\text {th }}$ ed. Rockville Maryland: The United States Pharmacopoeia; 2006.

6. Hong KM. Preparation and Characterization of Carboxymethyl Cellulose from Sugarcane Bagasse. IEEE International Symposium on the Applications of Ferroelectric; 2013.

7. Council of Europe. European Pharmacopoeia. $7^{\text {th }}$ ed. Strasbourg: Council of Europe; 2010-2012.

8. Ohwoavworhua FO, Adelakun TA, Okhamafe AO. Processing pharmaceutical grade microcrystalline cellulose from groundnut husk: Extraction methods and characterization. Int J Green Pharm 2009;3:97.
9. Fengel D, Wegener G. Kayu, Kimia, Ultrastruktur, Reaksi-reaksi. Yogyakarta: Gajah Mada Press; 1995.

10. Majewicz TG. Preparation of CMC with improved substituent uniformity using borax. United States: US Patent Office, Patent No.4306061; 1981

11. Harmita. Analisis Fisikokimia: Potensiometri and Spektroskopi. Jakarta: EGC; 2015.

12. Ferdiansyah MK, Marseno DW, Pranoto Y. Kajian karakteristik karboksimetil selulosa (CMC) dari pelepah kelapa sawit sebagai upaya diversifikasi bahan tambahan pangan yang halal. J Apl Teknol Pangan 2016;5:136-9

13. Elzagheid MI. Laboratory activities to introduce carbohydrates qualitative analysis to college students. World $\mathrm{J}$ Chem Educ 2018;6:82-6.

14. Basmal J, Andhita D, Sediarso S. Pengaruh alkalinisasi selulosa terhadap produksi sodium karboksimetil selulosa. J Penelit Perikan Indones 2005;11:1-13.

15. Sinko PJ. Farmasi Fisika dan Ilmu Farmasetika Martin. $5^{\text {th }}$ ed. Jakarta: EGC; 2011. 